\title{
Failure of a bioprosthetic mitral valve due to attachment of a residual chorda
}

\author{
KEITH M ROBERTS, PATRICIA V LAWFORD \\ From the University Departments of Pathology, Medical Physics, and Clinical Engineering, Medical School, \\ Sheffield
}

During the course of mitral valve replacement the recommended surgical practice is to excise the patient's chordae tendineae and a portion of each papillary muscle. ${ }^{12}$ This procedure has recently been challenged. ${ }^{3}$ We report a case in which inadvertent failure to excise a chorda and its associated papillary muscle was probably instrumental in causing failure of a mitral valve prosthesis.

\section{Case report}

A 74 year old woman with postrheumatic mitral valve disease presented initially at the age of 67 years with severe mitral regurgitation secondary to ruptured chordae of the posterior cusp. The mitral valve was replaced by a $29 \mathrm{~mm}$ Hancock heterograft, a satisfactory fit within the annulus being obtained. The prosthesis was sewn into position with multiple simple interrupted 2/0 Mersilene sutures. Her postoperative recovery was complicated by the Guillain-Barré syndrome, but was otherwise uneventful.

She presented again with mitral incompetence seven years after the initial operation. Cardiac catheter studies confirmed the presence of mitral incompetence and elective revision surgery was undertaken. At operation there was no evidence of auricular appendage thrombus but two abnormalities of the mitral valve prosthesis were identified. One of the leaflets adjacent to the anterolateral commissural area had become detached from its stent connections and the stent had become attached to a residual chorda. The valve was excised and replaced with a $31 \mathrm{~mm}$ Carpentier-Edwards bioprosthesis. The subsequent postoperative recovery was uneventful.

\section{MOR PHOLOGY OF THE EXCISED VALVE}

The sewing cuff and stent cover were invested with a dense layer of connective tissue ingrowth, which completely covered the fabric trim.

The striking feature of this valve was a pedicle of translucent white tissue, $10 \mathrm{~mm}$ long, which projected from the outflow aspect of the valve (fig 1). At its origin from the base of post 1 and the base ring between posts 1 and 3 this tissue became continuous with the host connective tissue covering the stent.

The valve cusps were flexible with no macroscopic evidence of thickening, wear, or calcification. The leaflets originating from post 2 were undamaged, but the one originating

Address for reprint requests: Dr $\mathrm{K} M$ Roberts, Department of Pathology, Medical School, Sheffield S10 2RX. from posts 1 and 3 was detached from its commissural attachments for a distance of $5 \mathrm{~mm}$. Pulse duplicator studies showed that these tears had caused the prolapse of leaflet $1-3$, resulting in incompetence of the valve with a forceful regurgitant jet. The reflux through the valve was found to be $34 \%$. On the outflow aspect of the valve the orifice was partially obstructed by the permanent inward deformation of posts 1 and 3. Close examination of the bare polypropylene stent showed that these posts were also deviating towards the pedicular attachment.

Microscopic examination showed that the papillary muscle and residual chorda had become attached to the stent post and were overgrown and thickened by mature connective tissue (fig 2). This connective tissue contained fine elastic fibres and occasional blood vessels. A fine, focal chronic inflammatory cell inflitrate was present in the tissue adjacent to the stent. The original chorda appeared thickened and while no active Aschoff nodules were identified a small circumscribed focus of fibrosis, consistent with a healed nodule, was present within the papillary muscle. The connective tissue of all three cusps was partially disrupted and the elastin content decreased. These changes were greatest in the torn cusps, which also contained fibrinoid material. Neocollagenisation was seen overlying the ventricularis at the base of each cusp: there was mild dystrophic calcification within this collagen. The surfaces of all the cusps lacked an endothelial layer. Granulation tissue, haemosiderin laden macrophages, and focal dystrophic calcification were present adjacent to the sewing ring, presumably being secondary to a paravalvular leak.

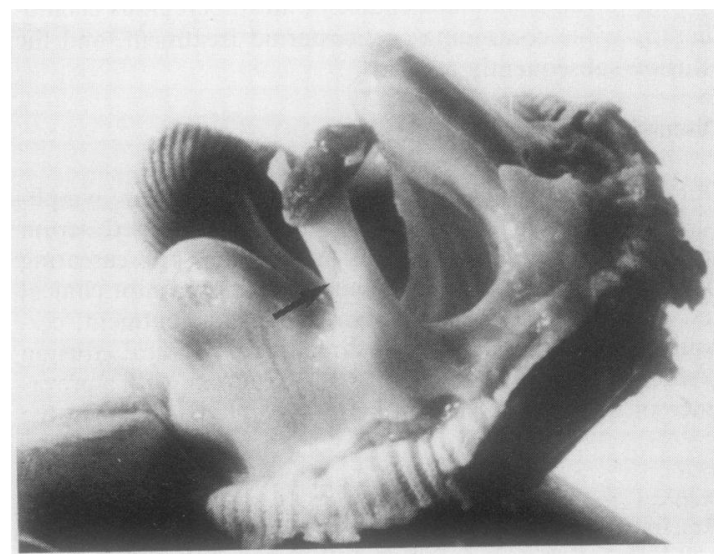

Fig 1 Excised mitral valve showing the attached chorda (arrow) and part of the papillary muscle. 


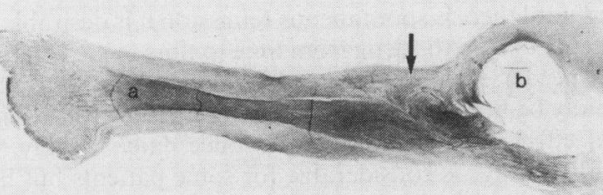

Fig 2 The pedicle with the original host chorda with its subendocardial elastic layer (a) and papillary muscle clearly visible. The connective tissue overgrowth connecting the chorda to the prosthesis is also visible (arrow). The space (b) is the site of the stent post. (Miller's elastin-van Gieson.)

\section{Discussion}

Stent post deformity in Hancock bioprosthetic valves necessitating reoperation has been reported previously. ${ }^{45}$ Only one of the valves was implanted as a mitral valve prosthesis. It was suggested that valvular dysfunction in the aortic position was caused by stent post compression due to a narrow aortic root; failure in the mitral position was attributed solely to "polymer creep," an aging characteristic of polypropylene. In each of these cases, however, all three stent posts were deformed. In the present case deformity of the stent was confined to the two posts adjacent to the point of attachment of the residual host chorda, and failure was confined to the leaflet between these stent posts. In this case therefore valve failure appears to have occurred as a result of stent deformity caused by attachment of the residual chorda.

Preservation of the papillary muscles and chordae tendineae during mitral replacement has been advocated to improve left ventricular function. This case provides evidence that preserving the chordae may result in valve failure and supports the established view that the chordae should be excised.

We are grateful to Mr B B Milstein for permission to publish this case, to Dr W B Tindale for pulse duplicator studies, to Mrs G Bilton for technical assistance, and to Mrs M Hogg for typing the manuscript.

\section{References}

1 Clarke DB. Prosthetic replacement of the mitral valve. In: Jackson JW, ed. Cardiothoracic surgery. 3rd ed. London: Butterworths, 1978:181-2.

2 Ison OW, Shemin RJ, Whiddon LL. Rheumatic mitral valve stenosis. In: Glenn WWL, ed. Thoracic and cardiovascular surgery. 4th ed. Norwalk, Connecticut: Appleton-CenturyCrofts, 1983:1300.

3 David TE, Strauss HD, Mecher E, Anderson JA, MacDonald IL, Buda AJ. Is it important to preserve the chordae tendinae and papillary muscles during mitral valve replacement? Can J Surg 1981;24:236-9.

4 Salomon NW, Copeland JG, Goldman S, Larson DF. Unusual complication of the Hancock porcine heterograft. Strut compression in the aortic root. $J$ Thorac Cardiovasc Surg 1979;77:294-6.

5 Borton AM, McIntosh C, Jones M, Roberts WC, Morrow AG. Inward stent post bending of a porcine bioprosthesis in the mitral position. Cause of bioprosthetic dysfunction. $J$ Thorac Cardiovasc Surg 1982;83:105-7. 